\title{
The consequences of patient charges for prescription drugs in Canada: a cross-sectional survey
}

\author{
Michael R. Law PhD, Lucy Cheng MSc, Ashra Kolhatkar MPH, Laurie J. Goldsmith PhD, \\ Steven G. Morgan PhD, Anne M. Holbrook MD PharmD, Irfan A. Dhalla MD MSc
}

\section{Abstract}

Background: Many Canadians face substantial out-of-pocket charges for prescription drugs. Prior work suggests that this causes some patients to not take their medications as prescribed; however, we have little understanding of whether charges for prescription medicines lead patients to forego basic needs or to use more health care services. Our study aimed to quantify the consequences of patient charges for medicines in Canada.

Methods: As part of the 2016 Canadian Community Health Survey, we designed and fielded cross-sectional questions to 28091 Canadians regarding prescription drug affordability, consequent use of health care services and trade-offs with other expenditures. We calculated weighted population estimates and proportions, and used logistic regression to determine which patient characteristics were associated with these behaviours.

Results: Overall, 5.5\% (95\% confidence interval 5.1\%-6.0\%) of Canadians reported being unable to afford 1 or more drugs in the prior year, representing $8.2 \%$ of those with at least 1 prescription. Drugs for mental health conditions were the most commonly reported drug class for cost-related nonadherence. About 303000 Canadians had additional doctor visits, about 93000 sought care in the emergency department, and about 26000 were admitted to hospital at the population level. Many Canadians forewent basic needs such as food (about 730000 people), heat (about 238000 ) and other health care expenses (about 239 000) because of drug costs. These outcomes were more common among females, younger adults, Aboriginal peoples, those with poorer health status, those lacking drug insurance and those with lower income.

Interpretation: Out-of-pocket charges for medicines for Canadians are associated with foregoing prescription drugs and other necessities as well as use of additional health care services. Changes to protect vulnerable populations from drug costs might reduce these negative outcomes.

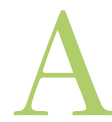

1l Canadian residents receive comprehensive public insurance for medically necessary hospital and physician services. As a result, patients do not have to pay for such services when they use them. However, prescription drugs are covered through a mix of public and private insurance plans and out-of-pocket payments by patients. ${ }^{1}$ Across the population, people make these payments for 4 reasons: 1) if they do not have drug coverage, 2) for drugs not covered by an insurance plan, 3) to satisfy the deductible requirements of public or private insurance coverage and 4) to pay the out-of-pocket per-prescription charges common to most public and private drug plans. ${ }^{2}$ Overall, these payments are substantial: in 2014, Canadian households paid an estimated $\$ 6.5$ billion out of pocket for prescription drugs $-22 \%$ of total prescription drug expenditures. ${ }^{3}$

As a result of having to pay for prescription drugs out of pocket, many Canadians skip doses or reduce dosages, delay refilling prescriptions or do not fill prescriptions at all to reduce their drug costs - a phenomenon known as costrelated nonadherence. ${ }^{4}$ The largest study to date showed that, in $2007,9.6 \%$ of Canadians who received a prescription did not take the drug as prescribed because of cost. ${ }^{4}$ Prior surveys have also suggested that Canada has higher rates of costrelated nonadherence than other countries with universal health care systems. ${ }^{5}$ Despite the frequency with which Canadians forego medicines owing to cost, little is known about

Competing interests: Michael Law has consulted for Health Canada and has acted as an expert witness for the Attorney General of Canada. No other competing interests were declared.

This article has been peer reviewed.

Correspondence to: Michael Law, michael.law@ubc.ca CMAJ Open 2018. DOI:10.9778/cmajo.20180008 
other consequences of patient charges for medicines. Survey studies in the United States have suggested that cost-related nonadherence has negative implications for health, and many people trade off drug costs with the costs of other basic needs. ${ }^{6,7}$ Surveys conducted to date in Canada, however, have not investigated such behaviours, nor have they investigated differences in the reporting of cost-related nonadherence by some groups (e.g., different ethnicities) or studied which drugs are not adhered to due to cost. ${ }^{4,8}$ Therefore, our study aimed to quantify the consequences of patient charges for medicines in Canada.

\section{Methods}

\section{Data sources}

Our study used the Canadian Community Health Survey, an annual telephone survey of the community-dwelling household population aged 12 years or more that covers $98 \%$ of the population. ${ }^{9}$ The survey uses separate sampling frames for adults aged 18 years or more and children aged $12-17$, with a target sample size over a 2-year collection period of 120000 for adults and 10000 for children across all Canadian provinces and territories. It has been frequently used in prior research studies on a wide range of topics, including estimates of cost-related nonadherence. ${ }^{4,10,11}$

Working in collaboration with Statistics Canada, we designed a module containing a broad set of questions regarding the consequences of out-of-pocket drug costs. ${ }^{12}$ All the questions in the module were based on validated questions used in previous studies or in previous versions of the Canadian Community Health Survey, ${ }^{4,7,8,13-16}$ Some questions were also informed by our team's recent qualitative study of cost-related nonadherence. ${ }^{17}$ The entire module underwent qualitative testing by Statistics Canada, which involved 13 in-depth one-onone interviews lasting 45-60 minutes that were conducted in French or English. We implemented all the recommendations that arose from the findings of the qualitative testing to try to reduce potential sources of bias. The module was fielded over the first 6 months of 2016. Questions assessing various consequences of out-of-pocket charges for drugs included:

- Cost-related nonadherence: 2 questions assessing various types of cost-related nonadherence (not filling, skipping doses, reducing dosage, delaying refilling) and what conditions foregone drugs were intended to treat. For this section, we selected common health conditions that are frequently treated with prescription drugs, such as heart disease, diabetes and mood disorders. We also asked how much the most recent foregone prescription was going to cost the patient.

- Health consequences that led to additional use of health care services: additional physician visits, emergency department visits and hospital stays resulting from cost-related nonadherence.

- Trade-offs: what was foregone in order to afford medicines (e.g., food, heat).

A single person from each household was invited to participate in the survey.

\section{Statistical analysis}

We used the survey questions to calculate national estimates of totals and proportions for specific outcomes. We developed 3 logistic regression models to determine what factors were associated with reporting 1) any type of cost-related nonadherence, 2) any health system consequence and 3) any spending trade-off. Our models included variables shown to be associated with cost-related nonadherence in prior studies, along with new variables such as ethnicity. ${ }^{4} 18$ When reporting results, we use the term "Aboriginal persons" to maintain consistency with the Canadian Community Health Survey question regarding Indigenous Peoples ("Are you an Aboriginal person?"). We estimated the first model using data for all Canadians who reported a prescription in the previous year, the second among all survey respondents and the third among all Canadians who reported any out-of-pocket prescription drug spending in the prior year.

To account for the complex sampling design of the survey, we used the provided survey weights for all estimates and models, and calculated confidence intervals using bootstrapping. ${ }^{19}$ As our initial examination revealed a total of $5.9 \%$ of missing data across all variables and a maximum of $3.6 \%$ missing data for any one variable, we used multiple imputation methods to fill in missing values for all independent variables. ${ }^{20} \mathrm{We}$ used a multistep process whereby we first imputed values for education level, as it had the highest number of missing values. We then used these imputed education values in the imputation of insurance and continued until all variables were complete. ${ }^{21} \mathrm{We}$ imputed 5 data sets for the regression models, which were then recombined to fully incorporate the necessary variance adjustments.

\section{Ethics approval}

This study was approved by the University of British Columbia Behavioural Research Ethics Board.

\section{Resullts}

\section{Descriptive characteristics}

The module was completed by 28091 respondents, with a Canada-wide response rate of $61.8 \%$. The descriptive characteristics and responses regarding cost-related nonadherence are shown in Table 1. Unadjusted rates of cost-related nonadherence were highest among younger adults, those with poorer self-reported health, those with lower incomes, those with no drug insurance, and those with higher use and spending on prescription drugs.

\section{Cost-related nonadherence}

Overall, 5.5\% (95\% confidence interval [CI] 5.06\%-6.00\%) of respondents reported 1 or more types of cost-related nonadherence in the previous year - an estimated \$1.69 million (95\% CI \$1.55 million-\$1.85 million) (Table 1). This represented $8.2 \%$ (95\% CI $7.48 \%-8.92 \%$ ) of those who received a prescription.

Our multivariate model showed that several characteristics were associated with higher odds of reporting cost-related 


\begin{tabular}{|c|c|c|c|}
\hline Variable & $\begin{array}{l}\text { No. of } \\
\text { respondents }\end{array}$ & $\begin{array}{l}\text { Weighted proportion of } \\
\text { total population }(95 \% \mathrm{Cl})\end{array}$ & $\begin{array}{l}\text { Weighted proportion with } \\
\text { cost-related nonadherence } \\
(95 \% \mathrm{Cl})\end{array}$ \\
\hline Overall & 28091 & - & $5.53(5.06-6.00)$ \\
\hline \multicolumn{4}{|l|}{ Sex } \\
\hline Female & 15024 & $50.66(50.66-50.66)$ & $6.50(5.81-7.19)$ \\
\hline Male & 13067 & $49.34(49.34-49.34)$ & $4.54(3.92-5.16)$ \\
\hline \multicolumn{4}{|l|}{ Age, yr } \\
\hline $12-17$ & 2511 & $8.69(8.43-8.95)$ & $2.06(1.32-2.80)$ \\
\hline $18-34$ & 5234 & $25.21(24.96-25.47)$ & $7.65(6.47-8.82)$ \\
\hline $35-44$ & 3568 & $14.70(14.20-15.20)$ & $6.04(4.77-7.31)$ \\
\hline $45-54$ & 4046 & $16.79(16.08-17.51)$ & $5.64(4.51-6.76)$ \\
\hline $55-64$ & 4897 & $16.13(15.63-16.64)$ & $5.01(4.00-6.01)$ \\
\hline $65-74$ & 4615 & $11.49(11.17-11.80)$ & $4.77(3.80-5.74)$ \\
\hline$\geq 75$ & 3220 & $6.98(6.67-7.30)$ & 3.35 (2.35-4.36) \\
\hline \multicolumn{4}{|c|}{ Self-reported health status } \\
\hline Excellent & 5996 & $23.99(23.13-24.86)$ & $2.88(2.10-3.66)$ \\
\hline Very good & 10221 & $37.32(36.41-38.23)$ & 3.64 (3.07-4.22) \\
\hline Good & 8016 & 27.39 (26.51-28.28) & $6.90(5.92-7.88)$ \\
\hline Fair & 2777 & $8.04(7.54-8.54)$ & $12.54(10.21-14.87)$ \\
\hline Poor & 1036 & $3.11(2.78-3.45)$ & $18.42(14.56-22.28)$ \\
\hline \multicolumn{4}{|c|}{ No. of chronic conditions } \\
\hline 0 & 12339 & $50.54(49.61-51.46)$ & $3.18(2.67-3.69)$ \\
\hline 1 & 7401 & $26.05(25.20-26.89)$ & $6.01(5.09-6.93)$ \\
\hline 2 & 4380 & $12.83(12.24-13.42)$ & $7.32(5.96-8.67)$ \\
\hline 3 & 2328 & $6.24(5.86-6.63)$ & $12.43(9.89-14.97)$ \\
\hline$\geq 4$ & 1643 & $4.34(3.98-4.70)$ & $14.82(12.31-17.34)$ \\
\hline \multicolumn{4}{|l|}{ Ethnic background } \\
\hline South Asian & 549 & $4.41(3.89-4.93)$ & $6.60(3.01-10.18)$ \\
\hline East Asian & 671 & $4.33(3.84-4.83)$ & $3.83(2.22-5.43)$ \\
\hline Aboriginal & 1349 & $3.61(3.27-3.95)$ & $10.94(7.95-13.92)$ \\
\hline White & 23029 & 72.25 (71.30-73.21) & $5.13(4.66-5.61)$ \\
\hline Other & 2493 & $15.39(14.58-16.21)$ & $6.30(4.76-7.84)$ \\
\hline \multicolumn{4}{|c|}{ Total household income, \$ } \\
\hline$<20000$ & 2675 & $7.11(6.62-7.60)$ & $11.14(8.85-13.43)$ \\
\hline 20 000-39 999 & 4940 & $13.76(13.13-14.39)$ & $9.44(7.92-10.95)$ \\
\hline $40000-59999$ & 4469 & $14.03(13.40-14.66)$ & $7.03(5.74-8.32)$ \\
\hline $60000-79999$ & 3631 & $12.93(12.27-13.60)$ & $5.56(4.27-6.84)$ \\
\hline $80000-99999$ & 3056 & $11.52(10.90-12.14)$ & $4.81(3.48-6.15)$ \\
\hline 100 000-149999 & 4905 & $19.87(19.07-20.68)$ & $3.57(2.69-4.45)$ \\
\hline$\geq 150000$ & 4415 & $20.78(19.94-21.62)$ & $2.27(1.59-2.94)$ \\
\hline \multicolumn{4}{|l|}{ Education } \\
\hline Secondary school & 6234 & 22.67 (21.83-23.52) & $6.69(5.59-7.8)$ \\
\hline Postsecondary & 15001 & $56.66(55.70-57.61)$ & $5.19(4.57-5.82)$ \\
\hline $\begin{array}{l}\text { Less than } \\
\text { secondary school }\end{array}$ & 6464 & $19.02(18.40-19.64)$ & $5.11(4.17-6.05)$ \\
\hline
\end{tabular}


nonadherence, including female sex, age 18-44 years, poorer health status, lower income status and lack of prescription drug insurance (full model results are presented in Appendix 1, available at www.cmajopen.ca/content/6/1/E63/ suppl/DC1). Of note, respondents identifying as Aboriginal had 1.92 (95\% CI 1.27-2.91) higher odds of reporting costrelated nonadherence. Most provinces had significantly higher rates of cost-related nonadherence than did Quebec, with the highest rates observed for British Columbia.

Drugs to treat almost every condition we asked about were foregone owing to cost-related nonadherence, with the highest prevalence for depression, anxiety or other mental health conditions (21.4\% [95\% CI 17.99-24.87]) (Table 2). The out-of-pocket cost of the most recent fore- gone prescription varied, with half of prescriptions costing \$51-\$200. Notably, nearly one-third of those who reported cost-related nonadherence (an estimated 427966 people) reported that their most recent forgone prescription would have cost $\$ 50$ or less.

\section{Health care system consequences}

Based on the number of survey respondents reporting health care system consequences, we estimated that 374461 Canadians (95\% CI 308 263-440 659) - 24.1\% [95\% CI 20.56\%$27.59 \%$ ] of those who reported cost-related nonadherence reported cost-related nonadherence that led to use of health care services they would not have needed otherwise (Table 3). This included 303341 people (95\% CI 242 651-364 032)

\begin{tabular}{|c|c|c|c|}
\hline Variable & $\begin{array}{l}\text { No. of } \\
\text { respondents }\end{array}$ & $\begin{array}{l}\text { Weighted proportion of } \\
\text { total population }(95 \% \mathrm{Cl})\end{array}$ & $\begin{array}{l}\text { Weighted proportion with } \\
\text { cost-related nonadherence } \\
(95 \% \mathrm{Cl})\end{array}$ \\
\hline \multicolumn{4}{|c|}{ Prescription drug insurance } \\
\hline Employer plan & 13573 & $51.58(50.60-52.55)$ & $3.44(2.92-3.96)$ \\
\hline Association plan & 2418 & $7.93(7.41-8.45)$ & $3.86(2.65-5.07)$ \\
\hline Government plan & 5896 & $16.56(15.90-17.23)$ & $7.13(6.09-8.18)$ \\
\hline None & 5331 & $19.46(18.65-20.26)$ & $11.29(9.69-12.88)$ \\
\hline \multicolumn{4}{|c|}{ No. of prescription drugs in prior 12 mo } \\
\hline 0 & 9108 & $36.48(35.57-37.40)$ & $0.88(0.63-1.13)$ \\
\hline 1 or 2 & 8212 & $30.70(29.78-31.63)$ & $6.96(6.01-7.92)$ \\
\hline 3 or 4 & 5195 & $16.11(15.44-16.79)$ & $8.47(7.29-9.65)$ \\
\hline$\geq 5$ & 4976 & $13.54(12.98-14.09)$ & $12.00(10.23-13.76)$ \\
\hline \multicolumn{4}{|c|}{ Out-of-pocket prescription drug spending in prior $12 \mathrm{mo}, \$$} \\
\hline 0 & 12133 & $47.34(46.37-48.31)$ & $1.68(1.35-2.01)$ \\
\hline $1-200$ & 8725 & $30.06(29.20-30.92)$ & $6.30(5.42-7.19)$ \\
\hline $201-500$ & 3185 & $9.56(9.04-10.08)$ & $13.50(11.10-15.90)$ \\
\hline $501-1000$ & 1722 & $4.79(4.44-5.14)$ & $15.37(12.31-18.43)$ \\
\hline$>1000$ & 1149 & $3.19(2.88-3.50)$ & $17.96(14.34-21.58)$ \\
\hline \multicolumn{4}{|l|}{ Province } \\
\hline British Columbia & 3757 & $13.25(13.25-13.25)$ & $8.11(6.74-9.47)$ \\
\hline Alberta & 3476 & $11.53(11.53-11.53)$ & $5.73(4.55-6.91)$ \\
\hline Saskatchewan & 1187 & $2.95(2.95-2.95)$ & $5.69(3.38-8.01)$ \\
\hline Manitoba & 1356 & 3.39 (3.39-3.39) & $5.51(3.75-7.27)$ \\
\hline Ontario & 8733 & $39.00(39.00-39.00)$ & 5.77 (4.85-6.68) \\
\hline Quebec & 6160 & $23.18(23.18-23.18)$ & $3.70(3.01-4.39)$ \\
\hline New Brunswick & 900 & $2.11(2.11-2.11)$ & $4.83(3.05-6.60)$ \\
\hline Nova Scotia & 1237 & $2.66(2.66-2.66)$ & $5.22(3.55-6.89)$ \\
\hline $\begin{array}{l}\text { Prince Edward } \\
\text { Island }\end{array}$ & 449 & $0.41(0.41-0.41)$ & $6.08(3.66-8.51)$ \\
\hline $\begin{array}{l}\text { Newfoundland and } \\
\text { Labrador }\end{array}$ & 836 & $1.50(1.50-1.50)$ & $4.51(2.68-6.34)$ \\
\hline
\end{tabular}




\begin{tabular}{|c|c|c|}
\hline Variable & Weighted total $(95 \% \mathrm{Cl})$ & $\begin{array}{c}\text { Weighted proportion } \\
\text { of population with cost-related } \\
\text { nonadherence }(95 \% \mathrm{Cl})\end{array}$ \\
\hline \multicolumn{3}{|c|}{ Condition treated by drugs foregone in prior $12 \mathrm{mo}$} \\
\hline $\begin{array}{l}\text { Depression, anxiety or other mental } \\
\text { health condition }\end{array}$ & 331866 (268 881-394 851) & $21.43(17.99-24.87)$ \\
\hline Arthritis or chronic pain & 252590 (190 989-314 192) & $16.31(12.68-19.76)$ \\
\hline $\begin{array}{l}\text { Heart disease, cholesterolemia or } \\
\text { high blood pressure }\end{array}$ & 244306 (191 779-296 833) & $15.78(12.60-18.95)$ \\
\hline Infection & 227983 (166 112-289 855) & $14.72(11.16-18.28)$ \\
\hline $\begin{array}{l}\text { Gut problems (e.g., peptic ulcer, } \\
\text { heartburn, bowel disease) }\end{array}$ & 175502 (136 984-214 020) & $11.33(8.96-13.71)$ \\
\hline $\begin{array}{l}\text { Asthma or chronic obstructive } \\
\text { pulmonary disease }\end{array}$ & 152800 (119 051-186 548) & $9.87(7.78-11.95)$ \\
\hline Diabetes & 127437 (93 474-161 399) & $8.23(6.13-10.33)$ \\
\hline Cancer & 9267 (4604-12 931) & $0.60(0.29-0.90)$ \\
\hline Other & 658065 (573 155-742 975) & $42.49(38.56-46.42)$ \\
\hline \multicolumn{3}{|c|}{ Cost of most recent foregone prescription, $\$$} \\
\hline $1-25$ & 164219 (120 569-207 868) & $11.31(8.54-14.08)$ \\
\hline $26-50$ & 263747 (214 091-313 403) & $18.16(15.20-21.13)$ \\
\hline $51-200$ & 749933 (650 338-849 528) & $51.65(47.18-56.12)$ \\
\hline $201-1000$ & 236765 (181 154-292 376) & $16.31(12.75-19.86)$ \\
\hline$>1000$ & 37326 (24 227-50 426) & $2.57(1.69-3.45)$ \\
\hline
\end{tabular}

Table 3: Additional use of health care services resulting from cost-related nonadherence

\begin{tabular}{|lccc|}
\hline Service & Weighted total $(95 \% \mathrm{Cl})$ & $\begin{array}{c}\text { Weighted proportion of } \\
\text { total population }(95 \% \mathrm{Cl})\end{array}$ & $\begin{array}{c}\text { Weighted proportion of } \\
\text { population with cost-related } \\
\text { nonadherence }(95 \% \mathrm{Cl})\end{array}$ \\
\hline Physician visit & $303341(242651-364032)$ & $0.99(0.79-1.19)$ & $19.50(16.11-22.89)$ \\
\hline Emergency department & $93295(63451-123139)$ & $0.31(0.21-0.40)$ & $6.00(4.18-7.82)$ \\
\hline Hospital stay & $26423(14502-38345)$ & $0.09(0.05-0.13)$ & $1.70(0.94-2.46)$ \\
\hline Any of the above & $374461(308263-440659)$ & $1.23(1.01-1.44)$ & $24.08(20.56-27.59)$ \\
\hline Note: $\mathrm{Cl}=$ confidence interval. & & & \\
\hline
\end{tabular}

who reported an additional physician visit, 93295 (95\% CI 63 451-123 139) who reported an additional emergency department visit and 26423 (95\% CI 14 502-38 345) who reported an additional hospital stay.

Logistic regression analysis showed that similar characteristics were associated with reporting health care system consequences as with cost-related nonadherence and foregoing spending (Appendix 2, available at www.cmajopen.ca/ content/6/1/E63/suppl/DC1). This included Aboriginal ethnicity, age 18-44 years, lower income, lack of drug insurance and number of chronic conditions. Notably, females had nearly twofold higher odds of reporting use of health care ser- vices as a result of cost-related nonadherence (odds ratio 1.94 [95\% CI 1.27-2.95]) compared to males.

\section{Trade-offs with other expenses}

Charges for prescription drugs led Canadians to reduce spending in other areas, including basic necessities. We estimated that 1.45 million (95\% CI 1.31 million-1.58 million) Canadians reduced spending on other areas of their budgets owing to drug costs (Table 4). This included 729706 people (95\% CI 637 166-822 246) spending less on food, 238611 (95\% CI 180 067-297 155) spending less on other health care expenses and 238178 (95\% CI $182771-293$ 584) spending 


\begin{tabular}{|lcc|}
\hline $\begin{array}{l}\text { Table 4: Expenditure areas in which trade-offs were made in order to afford prescription } \\
\text { drugs }\end{array}$ & Weighted total $(95 \% \mathrm{Cl})$ & $\begin{array}{c}\text { Weighted proportion of } \\
\text { total population }(95 \% \mathrm{Cl})\end{array}$ \\
\hline Area & $836885(735937-937832)$ & $2.74(2.41-3.07)$ \\
\hline Leisure or vacation & $729706(637166-822246)$ & $2.39(2.08-2.69)$ \\
\hline Food & $375774(307488-444060)$ & $1.23(1.01-1.45)$ \\
\hline $\begin{array}{l}\text { Car, public transit or other } \\
\text { transportation costs }\end{array}$ & $238611(180$ 067-297 155) & $0.78(0.59-0.97)$ \\
\hline $\begin{array}{l}\text { Other health care expenses } \\
\text { for self or anyone else in } \\
\text { household }\end{array}$ & $238178(182771-293584)$ & $0.78(0.60-0.96)$ \\
\hline $\begin{array}{l}\text { Heat } \\
\text { Housing }\end{array}$ & $206056(147832-265289)$ & $0.67(0.48-0.86)$ \\
\hline $\begin{array}{l}\text { Other expenses not already } \\
\text { mentioned }\end{array}$ & $297882(231905-363858)$ & $0.97(0.76-1.19)$ \\
\hline Any of the above & $1447183(1313582-1580785)$ & $4.73(4.30-5.17)$ \\
\hline Note: Cl = confidence interval. & & \\
\hline
\end{tabular}

less on heat. Our multivariate results suggested that many of the same factors were associated with spending less in other areas as with reporting cost-related nonadherence, including being a younger adult (age 18-44 yr), lacking prescription drug insurance, lower income and poorer health status (Appendix 3, available at www.cmajopen.ca/content/6/1/E63/ suppl/DC1).

\section{Interpretation}

We found that out-of-pocket charges for prescription drugs had important implications, leading patients to not take prescription drugs, to use more health care services than they would have otherwise and to forego other household spending. These behaviours were all more common among younger adults, lower-income groups and those without drug insurance. We also found significant associations, with increased rates of 2 or more behaviours for females, Aboriginal peoples and those with poorer health status.

Our findings support recommendations that prescribers consider whether patients can afford their medications. ${ }^{22}$ Our findings also suggest that prescribers might consider asking whether patients are making related trade-offs. Furthermore, prescribers should be aware of the higher potential for costrelated nonadherence, and related trade-offs, in female patients, Aboriginal persons and those with poorer health status. The characteristics of Canadians who engaged in tradeoffs and experienced health consequences appear similar to those of people experiencing cost-related nonadherence in other countries. For example, in the US, the rate of cutting back on other spending was higher among women, younger people, nonwhite people and those with low income. ${ }^{6}$ High rates of trade-offs have also been shown among patients with chronic obstructive pulmonary disease in Australia and those with arthritis and diabetes in the US..$^{23-25}$
Prescribers should also be aware that cost-related nonadherence was not limited to expensive medications. This is consistent with our team's qualitative findings suggesting that patients' very individual decisions about taking particular prescriptions are driven primarily by their own assessment of the importance of the medication and the flexibility of their budget. ${ }^{17}$ Taken together, this indicates that, although certain personal characteristics are likely to help identify patients who are at higher risk for cost-related nonadherence or trade-offs, clinicians should be aware that the decisions patients make are likely very individual. Changing clinical systems to support discussions with patients, with comparative information on drug costs, would also likely help physicians consider what to prescribe, with a view to minimizing the negative effects of cost-related nonadherence. ${ }^{26}$ Finally, clinicians should consider that drugs for mental health conditions were the most commonly reported drug class for cost-related nonadherence and should be particularly cognizant of cost with patients with these disorders.

The higher rate of cost-related nonadherence among Aboriginal peoples likely results from structural barriers in the health care system. First, although the First Nations and Inuit Health Branch of Health Canada provides universal prescription drug coverage to eligible patients through the NonInsured Health Benefits Program, more than half of Aboriginal people in Canada do not qualify for this coverage. ${ }^{27}$ Second, direct reimbursement is available to clients of this program only if they fill prescriptions at pharmacies registered with the program. Otherwise, clients must pay the full cost of their drug upfront and submit a claim for reimbursement. ${ }^{28} \mathrm{We}$ are unaware of any public record of registered pharmacies, so the extent to which this might present a barrier is unclear. Finally, there is a large and growing body of literature regarding the structural racism and violence Indigenous patients face when accessing primary health care in Canada. These experiences 
have a significant impact on health..$^{29-32}$ These routine experiences of discomfort and shame when interacting with the health care system can contribute to higher rates of cost-related nonadherence, for example, because Indigenous patients may avoid consultations with physicians and pharmacists or may cut visits short without obtaining the necessary information. ${ }^{33}$

The prevalence of cost-related nonadherence in our study, $8.2 \%$, is slightly lower than comparable past estimates: we previously found that $9.6 \%$ of those with a prescription in 2007 experienced cost-related nonadherence. ${ }^{4}$ This modest reduction may be the result of several policy and demographic factors' acting to provide better coverage to some segments of the population. For example, price negotiations by the provinces have likely resulted in more extensive listings on public drug plans. At the same time, more generic alternatives have become available for widely prescribed medicines, ${ }^{34}$ and large decreases in generic drug prices have been stimulated by changes in provincial policies. ${ }^{35}$ Finally, as the population has aged, a higher proportion of patients will have "aged into coverage" in provinces with age-based public drug entitlements, such as Ontario.

\section{Limitations}

As with any survey-based analysis, our results are necessarily based on patient report. Thus, they may be subject to recall and social desirability bias. However, recall bias (if present) would be likely to have made our estimates conservative. ${ }^{36}$ Self-report may also mean the reported trade-offs and additional use of health care services may not have been causally related to drug charges. However, we know from prior studies that out-of-pocket costs for prescription drugs can be related to higher use of other health care services. ${ }^{37}$ Furthermore, although we had hoped to link cost-related nonadherence and trade-offs with specific insurance design features (such as coinsurance and deductibles), we found in pilot testing that the vast majority of respondents could not reliably describe these features of their own coverage. Therefore, we did not include them in our final survey instrument.

\section{Conclusion}

Our results confirm that cost remains a barrier to obtaining prescription medicines for many Canadians. This exists for medicines across a variety of clinical conditions and costs and results in adverse consequences for both patients and the health care system. There are many avenues through which governments might act to reduce cost-related nonadherence. ${ }^{38}$ Policies that reduce cost-related nonadherence should be investigated to see whether they reduce use of health care services that is a consequence of cost-related nonadherence and also allow Canadians who are currently disadvantaged in access to prescription drugs to avoid trade-offs with other essential spending.

\section{References}

1. Daw JR, Morgan SG. Stitching the gaps in the Canadian public drug coverage patchwork? A review of provincial pharmacare policy changes from 2000 to 2010. Health Policy 2012;104:19-26.

2. Kratzer J, McGrail K, Strumpf E, et al. Cost-control mechanisms in Canadian private drug plans. Healthc Policy 2013;9:35-43.

3. National health expenditure trends, 1975 to 2016. Ottawa: Canadian Institute for Health Information; 2016.
4. Law MR, Cheng L, Dhalla IA, et al. The effect of cost on adherence to prescription medications in Canada. CMA7 2012;184:297-302.

5. Morgan SG, Lee A. Cost-related non-adherence to prescribed medicines among older adults: a cross-sectional analysis of a survey in 11 developed countries. BM7 Open 2017;7:e014287.

6. Heisler M, Wagner TH, Piette JD. Patient strategies to cope with high prescription medication costs: Who is cutting back on necessities, increasing debt, or underusing medications? 7 Behav Med 2005;28:43-51.

7. Soumerai SB, Pierre-Jacques M, Zhang F, et al. Cost-related medication nonadherence among elderly and disabled Medicare beneficiaries: a national survey 1 year before the Medicare drug benefit. Arch Intern Med 2006;166:1829-35.

8. Kennedy J, Morgan S. Cost-related prescription nonadherence in the United States and Canada: a system-level comparison using the 2007 International Health Policy Survey in Seven Countries. Clin Ther 2009;31:213-9.

9. Canadian Community Health Survey (CCHS) - annual component: user guide 2007-2008 microdata files. Ottawa: Statistics Canada; 2009. Available: www. statcan.gc.ca/imdb-bmdi/document/3226_D7_T9_V6-eng.pdf (accessed 2011 July 27).

10. Quan H, Fong A, Coster CD, et al. Variation in health services utilization among ethnic populations. CMA7 2006;174:787-91.

11. McIntyre RS, Konarski JZ, Wilkins K, et al. The prevalence and impact of migraine headache in bipolar disorder: results from the Canadian Community Health Survey. Headache 2006;46:973-82.

12. Canadian Community Health Survey (CCHS) rapid response fanuary-7une 2016 prescriptions - cost-related non-adberence. Ottawa: Statistics Canada; 2016. Available: http://www23.statcan.gc.ca/imdb/p3Instr.pl? Function= assembleInstr\&Item_Id=299879 (accessed 2017 Oct. 13).

13. Bengle R, Sinnett S, Johnson T, et al. Food insecurity is associated with costrelated medication non-adherence in community-dwelling, low-income older adults in Georgia. 7 Nutr Elder 2010;29:170-91.

14. Briesacher BA, Ross-Degnan D, Wagner AK, et al. Out-of-pocket burden of health care spending and the adequacy of the Medicare Part D low-income subsidy. Med Care 2010;48:503-9.

15. Kennedy J, Tuleu I, Mackay K. Unfilled prescriptions of Medicare beneficiaries: prevalence, reasons, and types of medicines prescribed. 7 Manag Care Pharm 2008;14:553-60.

16. Madden JM, Graves AJ, Zhang F, et al. Cost-related medication nonadherence and spending on basic needs following implementation of Medicare Part D. 7AMA 2008;299:1922-8.

17. Goldsmith LJ, Kolhatkar A, Popowich D, et al. Understanding the patient experience of cost-related non-adherence to prescription medications through typology development and application. Soc Sci Med 2017;194:51-9.

18. Briesacher BA, Gurwitz JH, Soumerai SB. Patients at-risk for cost-related medication nonadherence: a review of the literature. 7 Gen Intern Med 2007;22: 864-71.

19. Bootvar user guide (Bootvar 3.2-version SAS). Ottawa: Statistics Canada; 2013.

20. Horton NJ, Lipsitz SR. Multiple imputation in practice: comparison of software packages for regression models with missing variables. Am Stat 2001;55: 244-54.

21. Berglund P. An introduction to multiple imputation of complex sample data using SAS ${ }^{\circledR}$ version 9.2. Cary (NC): SAS Institute; 2010. Available: http:// support.sas.com/resources/papers/proceedings10/265-2010.pdf (accessed 2017 Sept. 14).

22. Tamblyn R, Eguale T, Huang A, et al. The incidence and determinants of primary nonadherence with prescribed medication in primary care: a cohort study. Ann Intern Med 2014;160:441-50.

23. Essue B, Kelly P, Roberts M, et al. We can't afford my chronic illness! The out-of-pocket burden associated with managing chronic obstructive pulmonary disease in western Sydney, Australia. 7 Health Serv Res Policy 2011;16:226-31.

24. Piette JD, Heisler M, Wagner TH. Problems paying out-of-pocket medication costs among older adults with diabetes. Diabetes Care 2004;27:384-91.

25. Martin KR, Shreffler J, Schoster B, et al. Coping with prescription medication costs: a cross-sectional look at strategies used and associations with the physical and psychosocial health of individuals with arthritis. Ann Behav Med 2012;44: 236-47.

26. Gorfinkel I, Lexchin J. We need to mandate drug cost transparency on electronic medical records. CMA7 2017;189:E1541-2.

27. Aboriginal Peoples in Canada: First Nations people, Métis and Inuit - National Household Survey, 2011. Ottawa: Statistics Canada; 2013. Cat no 99-011X2011001. Available: www12.statcan.gc.ca/nhs-enm/2011/as-sa/99-011-x/99 -011-x2011001-eng.cfm (accessed 2017 Dec. 4).

28. Pharmacy benefit information - non-insured health benefits. Ottawa: Health Canada; 2005. Available: https://www.canada.ca/en/health-canada/services/ first-nations-inuit-health/non-insured-health-benefits/benefits-information/ pharmacy-benefit-information-first-nations-inuit-health.html (accessed 2017 Dec. 4).

29. Browne AJ, Smye VL, Rodney $\mathrm{P}$, et al. Access to primary care from the perspective of Aboriginal patients at an urban emergency department. Qual Health Res 2011;21:333-48.

30. Tang SY, Browne AJ. 'Race' matters: racialization and egalitarian discourses involving Aboriginal people in the Canadian health care context. Ethn Health 2008; 13:109-27. 
31. Goodman A, Fleming K, Markwick N, et al.; Western Aboriginal Harm Reduction Society. "They treated me like crap and I know it was because I was Native": the healthcare experiences of Aboriginal peoples living in Vancouver's inner city. Soc Sci Med 2017;178:87-94.

32. Kurtz DLM, Nyberg JC, Van Den Tillaart S, et al. Silencing of voice: an act of structural violence: urban Aboriginal women speak out about their experiences with health care. Int 7 Indig Health 2008;4:53-63.

33. Stoneman J, Taylor SJ. Improving access to medicines in urban, regional and rural Aboriginal communities - Is an expansion of Section 100 the answer? Rural Remote Health 2007;7:738-45.

34. NPDUIS CompassRx, 1st edition: annual public drug plan expenditure report 2012/13. Ottawa: Patented Medicines Pricing Review Board; 2016. Available: www.pmprb-cepmb.gc.ca/view.asp?ccid=1159\&lang=en (accessed 2017 Aug. 3).

35. Law MR, Kratzer J. The road to competitive generic drug prices in Canada. CMA7 2013;185:1141-4.

36. Evans C, Crawford B. Patient self-reports in pharmacoeconomic studies. Their use and impact on study validity. Pharmacoeconomics 1999;15:241-56.

37. Tamblyn R, Laprise R, Hanley JA, et al. Adverse events associated with prescription drug cost-sharing among poor and elderly persons. FAMA 2001;285: 421-9.

38. Tang KL, Ghali WA, Manns BJ. Addressing cost-related barriers to prescription drug use in Canada. CMA7 2014;186:276-80.

Affiliations: Centre for Health Services and Policy Research (Law, Cheng, Kolhatkar); School of Population and Public Health (Law, Cheng, Kolhatkar, Morgan), University of British Columbia, Vancouver, BC; Faculty of Health Sciences (Goldsmith), Simon Fraser University, Burnaby, BC; Division of Clinical Pharmacology and Toxicology (Holbrook), Department of Medicine, McMaster University, Hamilton,
Ont.; Health Quality Ontario (Dhalla); Li Ka Shing Knowledge Institute (Dhalla), St. Michael's Hospital; Institute for Clinical Evaluative Sciences (Dhalla), Toronto, Ont.

Contributors: Michael Law, Laurie Goldsmith, Steven Morgan, Anne Holbrook and Irfan Dhalla contributed to study conception. Michael Law, Lucy Cheng, Ashra Kolhatkar, Laurie Goldsmith, Steven Morgan, Anne Holbrook and Irfan Dhalla contributed to study design. Michael Law acquired the data and drafted the manuscript. Lucy Cheng, Ashra Kolhatkar, Laurie Goldsmith, Steven Morgan, Anne Holbrook and Irfan Dhalla critically revised the manuscript for important intellectual content. All of the authors contributed to data analysis and interpretation, gave final approval of the version to be published and agreed to be accountable for all aspects of the work.

Funding: This analysis was funded by operating grant MOP-126020 and Foundation Scheme Grant FDN-148412 from the Canadian Institutes of Health Research. Michael Law received salary support through a Canada Research Chair in Access to Medicines and a Michael Smith Foundation for Health Research Scholar Award.

Disclaimer: The views expressed in this publication do not necessarily represent the views of Health Quality Ontario and should not be construed as representing an official position.

Supplemental information: For reviewer comments and the original submission of this manuscript, please see www.cmajopen.ca/content/6/1/ E63/suppl/DC1. 